\title{
Hepatitis $B$ vaccination in preterm infants
}

\author{
Fu-Yuan Huang, Ping-Ing Lee, Chin-Yun Lee, Li-Min Huang, Luan-Yin Chang,
} $\mathrm{Su}-\mathrm{Chin} \mathrm{Liu}$

\begin{abstract}
Aim-To investigate the immunogenicity and safety of existing recommendations for hepatitis $B$ vaccination in preterm infants.

Methods-Recombinant hepatitis B vaccine (H-B-VAX II, $5 \mu$ ger dose) was given to 85 preterm infants divided into two groups, using two different schedules. Forty four group A infants with birthweights of $<2000 \mathrm{~g}$ received three doses at 1,2 , and 7 months of age. Forty one group $B$ infants with birthweights of $\geqslant 2000 \mathrm{~g}$ received three doses at 0,1 , and 6 months of age.

Results-After vaccination, 42 infants from group A $(95 \%)$ and 37 infants from group B $(90 \%)$ developed protective levels of antibody. The final seropositive rate and the geometric mean concentration of hepatitis $B$ surface antibody between the two groups were not significantly different. The immune response of preterm infants to hepatitis $B$ vaccines was similar to that of term infants in a previous study. Conclusions-Preterm infants can be given hepatitis $B$ vaccines using one of the above two different schedules, at a cutoff birthweight of $2000 \mathrm{~g}$.

(Arch Dis Child 1997;77:F135-F138)
\end{abstract}

Keywords: hepatitis B vaccine, prematurity, antibodies

The carrier rate for hepatitis $\mathrm{B}$ in the Taiwanese has been reported to be 15 to $20 \%$, with perinatal hepatitis $\mathrm{B}$ virus (HBV) transmission accounting for $40-50 \%$ of the carrier pool. ${ }^{1-4}$ Many studies have shown that hepatitis vaccination can prevent both vertical and horizontal transmission of $\mathrm{HBV}^{5-8}$ Therefore, a mass hepatitis $B$ vaccination programme was started in Taiwan in $1984 . .^{\circ}$ A recent serological survey in Taipei showed that the overall prevalence of hepatitis B surface antigen ( $\mathrm{HBsAg}$ ) in children below 12 years of age had dropped from $9.8 \%$ in 1984 to $1.3 \%$ in $1994 .{ }^{10}$ The current policy is to give three doses of recombinant hepatitis $B$ vaccine to term infants at birth, and at 1 month and 6 months of age. A dose of hepatitis B immunoglobulin is given at birth to infants of hepatitis $\mathrm{B}$ e antigen (HBeAg) positive mothers. However, an unresolved problem with vaccination is that the optimal vaccination schedule for preterm infants has not been established. Some studies have revealed that the antibody response to hepatitis B vaccines may be lower in premature infants given the vaccines beginning at birth than if the initial dose is delayed until they are older or weigh more than 2000 g. ${ }^{11-13}$ However, in another study, starting hepatitis B vaccination at birth was reported to elicit a similar antibody response in preterm and term infants. ${ }^{14}$ As a result it has been difficult to integrate these data and to establish an optimal schedule, because the studies enrolled a limited number of cases, ${ }^{12}{ }^{13}$ used different vaccination schedules, ${ }^{14}$ and did not include preterm infants with birthweights above 2000 g. $^{11}$ According to current recommendations by the Advisory Committee for Immunization Practice of the US Public Health Service, preterm infants with birthweights $>2000 \mathrm{~g}$ receive recombinant hepatitis $B$ vaccines according to the same schedule as that given for full term infants. For preterm infants with birthweights $<2000 \mathrm{~g}$, the first dose of vaccine is delayed until just before hospital discharge if the infant weighs $2 \mathrm{~kg}$ or more, or until about 2 months of age when other routine immunisations are given. The remaining two doses of vaccine are given one to two months after the first dose and at 6 to 18 months of age, respectively. Hepatitis $\mathrm{B}$ immunoglobulin is given at birth to all preterm infants of $\mathrm{HBsAg}$ positive mothers. We enrolled 85 preterm infants into a prospective study to compare the safety and immunogenicity of hepatitis $B$ vaccination, with the first dose delayed until 1 month of age in infants weighing under $2000 \mathrm{~g}$ at birth, administered according to standard recommendations for infants weighing over $2000 \mathrm{~g}$ at birth.

\section{Methods}

Eighty five neonates with gestational ages of less than 37 weeks and birthweights $<2500 \mathrm{~g}$ were enrolled in this study between November 1993 and January 1995, after obtaining parental consent. Preterm infants with life threatening illness and those born to HBV carrier mothers were excluded from the study. None of the enrolled infants had received exchange transfusion or intravenous immunoglobulin treatment. There were 11 twins and three triplets. The postnatal course was complicated by respiratory distress syndrome in 17 infants. Blood samples were obtained from the mothers after delivery to recheck markers of $\mathrm{HBV}$ infection. A recombinant hepatitis B vaccine, $5 \mu \mathrm{g}$ per dose of H-B-VAX II (Merck, Sharp and Dohme, West Point, PA), was used in this study. This vaccine is equivalent to Recombivax in the United States. Infants were divided into two groups. Group A included 44 infants with birth weights $<2000 \mathrm{~g}$ who received three doses of hepatitis $B$ vaccine at 1,2 , and 7 months of age. Their gestational ages ranged from 28 to 37 (mean (SD) 33.1 (1.9)) weeks 
Table 1 Hepatitis B markers

\begin{tabular}{llrrr}
\hline & \multicolumn{3}{c}{ Anti-HBs $(\mathrm{mU} / \mathrm{ml})$} & \\
\cline { 2 - 4 } & $\geqslant 10$ & GMC & $\begin{array}{l}\text { 95\% confidence } \\
\text { interval of GMC }\end{array}$ & Anti-HBc-positive \\
\hline Group $A(n=44)$ & & & & \\
Pre-vaccination & $18(41 \%)$ & 257 & $114-579$ & $28(64 \%)$ \\
After injection 2 & $36(82 \%)$ & 95 & $68-134$ & $4(9 \%)$ \\
After injection 3 & $42(95 \%)$ & 257 & $155-426$ & 0 \\
Group B $(n=41)$ & $29(71 \%)$ & 248 & $120-513$ & $28(68 \%)$ \\
Pre-vaccination & $35(85 \%)$ & 55 & $36-83$ & $8(20 \%)$ \\
After injection 2 & $37(90 \%)$ & 194 & $116-323$ & 0 \\
After injection 3 & & & & \\
\hline
\end{tabular}

^ Geometric mean concentration.

and their birthweights ranged from 1090 to 1980 (mean (SD) 1731 (212)) g. The body weights ranged between 1200 and 3300 (mean (SD) $2356+(418)) \mathrm{g}$ when they received the first dose of vaccine. Five infants weighed less than $2000 \mathrm{~g}$ when the vaccination was started. Blood samples were collected at 1, 7, and 10 months of age for serology. Group B included 41 infants with birthweights $<2500 \mathrm{~g}$ and $>2000 \mathrm{~g}$ who received three doses of hepatitis $B$ vaccine at 0,1 , and 6 months of age. Their gestational ages ranged from 32 to 37 (mean (SD) 34.8 (1.4)) weeks and their birthweights ranged from 2000 to 2490 (mean (SD) 2214 (137)) g. Blood samples were collected at 0, 6, and 9 months of age for serology.

Assessment of adverse reactions was done by the attending nurse when the infant stayed in hospital. At each visit for vaccination after discharge, a checklist of possible adverse reactions was given to parents. The parents were instructed to take rectal body temperature twice a day and to observe and record any adverse reactions for seven days after vaccination. A well trained nurse contacted the parents on the third day after vaccination, and reviewed and recorded all vaccine related reactions. At the next visit, the checklist was collected for analysis.

If the last blood sample was negative for hepatitis B surface antibody (anti-HBs), an additional dose of hepatitis $\mathrm{B}$ vaccine was given at 1 year of age, and the anti-HBs titre was assessed one month later. Anti-HBs, hepatitis B core antibody (anti-HBc), and HBsAg were tested using a radioimmunoassay (Abbott Laboratories, North Chicago, IL). The presence of anti-HBs was determined using a standard curve generated by assaying five antiHBs standards containing $0,15,40,75$, and $150 \mathrm{mU} / \mathrm{ml}$ of antibody, derived from the World Health Organization anti-HBs standards.

Anti-HBs was considered positive when its concentration exceeded $10 \mathrm{mU} / \mathrm{ml}$. Only samples positive for anti-HBs were included in the calculation of the geometric mean concentration for anti-HBs. Student's $t$ test was used to compare the geometric mean concentrations for anti-HBs between groups. Differences in prevalence between groups were examined using the $\chi^{2}$ test with Yates' correction. Within each group, linear regression was used to examine the correlation between two numerical variables. Values of anti-HBs were log transformed in these regressional analyses.

\section{Results}

Three months after the last dose of vaccine, the seropositive rate for anti-HBs was 95\% (42/44) in group A and $90 \%$ (37/41) in group B. Six infants who lacked anti-HBs after three doses of vaccine received an additional dose of hepatitis $B$ vaccine at 1 year of age. Three of them developed protective anti-HBs one month later. No significant difference in the seropositivity for anti-HBs between groups $\mathrm{A}$ and $\mathrm{B}$ was found three months after the third dose (table 1). The geometric mean concentration of antiHBs was slightly higher in group A than in group $B$ at the time of administration of the third dose of vaccine $(P=0.039)$. The mean titre of anti-HBs before the first dose and three months after the third dose did not differ significantly between the two groups (table 1).

All blood samples were negative for HBsAg. Maternally acquired anti-HBc was detected in $28(64 \%)$ group A infants and 28 (68\%) group $\mathrm{B}$ infants when blood was first sampled, but had disappeared by the end of follow up. Each time blood was sampled, the seropositivity for anti-HBc was not significantly different between the two groups (table 1). No significant adverse reactions associated with the vaccine were observed.

Whenever blood was sampled in either group, there was no evidence that mean anti-HBs titres were significantly affected by the presence of respiratory distress syndrome at birth. Antibody titres in twins and triplets were similar to those in singletons. Regressional analysis showed that anti-HBs values were not significantly correlated with gestational age or birthweight within each group, nor were they correlated with body weight at 1 month of age in group A infants. Regressional analysis was also used to examine the influence of maternal anti-HBs concentration at delivery on the immune response of the infant. In group A maternal anti-HBs concentrations were significantly correlated with those of infants at 1 month of age $(r=0.877, P<0.001)$, but not with those at 10 months of age $(r=0.167, \mathrm{P}>$ 0.05). Similarly, maternal anti-HBs concentrations in group B were significantly correlated with those of infants at birth $(r=0.905, P<$ $0.001)$, but not with those at 9 months of age ( $\mathrm{r}$ $=0.228, \mathrm{P}>0.05)$.

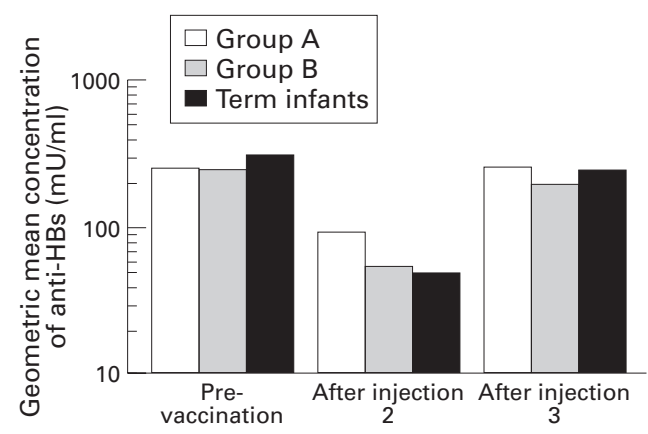

Figure 1 Geometric mean concentrations of anti-HBs in this study compared with those of term infants in a previous study $y^{15}$. 


\section{Discussion}

This study shows that the vaccination schedule adopted induces a satisfactory immune response in preterm infants. We have already conducted a study of hepatitis $B$ vaccine on 103 full term infants born to HBsAg negative mothers. ${ }^{15}$ Each infant received $10 \mu \mathrm{g}$ doses of Engerix-B (SmithKline Beecham Biologicals, SB, Rixensart, Belgium) at birth, 6 weeks and 5.5 months of age. Blood samples were taken at $0,5.5$, and 9 months of age for serology. At the end of the study the seropositive rate for anti-HBs was $96 \%$ (99/103), which was not significantly different from that in either group A or group B in this study ( $\chi^{2}$ test with Yates' correction, $\mathrm{P}>0.05)$. The final geometric mean concentration of anti-HBs was 248 $\mathrm{mU} / \mathrm{ml}$, which was also not significantly different from that in either group A or group B (Student's $t$ test, $\mathrm{P}>0.05$ ) (fig 1 ). Our previous study showed that $10 \mu \mathrm{g}$ Engerix-B was equivalent in immunogenicity and efficacy to $5 \mu \mathrm{g} \mathrm{H}-\mathrm{B}-\mathrm{VAX}$ II. ${ }^{16}$ Nevertheless, the two study results may not be directly comparable because different vaccines were used. It can only imply that the immunogenicity of our hepatitis B vaccination schedule is satisfactory in preterm infants.

There are some subtle differences in our results compared with those of other studies. ${ }^{11-14}$ The reasons for these discrepancies may be clarified by carefully reviewing the data. In a study of preterm infants in Thailand, three $10 \mu \mathrm{g}$ doses of Engerix-B were given at birth, 1 month, and 6 months of age. A protective titre of anti-HBs developed in 11 of $14(78 \%)$ infants with gestational ages of 28 to 32 weeks and in all 11 infants with gestational ages of 33 to 37 weeks. ${ }^{13}$ Although the seropositive rate for infants with shorter gestational ages seems to be lower than that of the other group, the difference is not significant. With a larger sample size, as in the present study, we did not find any correlation between the gestational age and the immune response in either group of infants.

A study in Italy showed that all of 37 preterm infants developed protective titres of anti-HBs after three doses of $10 \mu \mathrm{g}$ Engerix-B, starting at birth. ${ }^{12}$ Logistic regression showed that the chance of being a high responder was positively correlated with an increase in gestational age. This result implies that a shorter gestational age was associated with a lower final antibody concentration. ${ }^{17}$ However, it should be noted that although there were 371 term infants, there were only 37 preterm infants in the regressional analysis. Such an analysis was therefore performed mainly on data from term infants, and such a conclusion cannot be directly applied to preterm infants. Although group A infants may have had a lower antibody titre when they were vaccinated at birth, the influence of gestational age on antibody titre was not discernible when different schedules were used for preterm infants with different birthweights.

A study in the Netherlands concluded that the immune response of preterm infants to hepatitis $B$ vaccine was not significantly different from those of term infants. ${ }^{14}$ The authors suggested that there is no need to delay vaccination in preterm infants with birthweights < 2000 g. ${ }^{14}$ However, their conclusion was not very convincing because in that study a total of 46 preterm infants had received 11 different combinations of different types of vaccine, different doses of vaccine, and different vaccination schedules. ${ }^{14}$ The data reported by Lau et al have clearly shown that preterm infants with birthweights $<1750 \mathrm{~g}$ respond poorly to hepatitis $B$ vaccines if the vaccination is started at birth. ${ }^{11}$

In Lau et al's study, a group of preterm infants with birthweights of $<1750 \mathrm{~g}$ received the first dose of $10 \mu \mathrm{g}$ Engerix-B when they weighed $>2000 \mathrm{~g}$. The immune responses of these preterm infants were not as competent as those of term infants. ${ }^{11}$ In the present study 39 group A infants weighed more than $2000 \mathrm{~g}$ when the vaccination programme was started. The vaccination would have been started at an earlier postnatal age if a body weight of $2000 \mathrm{~g}$ had been chosen as the cutoff for initiating vaccination. Our study also showed that final anti-HBs values were not significantly correlated with body weights at 1 month of age in group A infants. Therefore, delaying the first dose of vaccine until 1 month of age for preterm infants with birthweights $<2000 \mathrm{~g}$ seems to be a reasonable recommendation. This finding supports the guidelines of the Advisory Committee for Immunization Practice, Department of Health, Republic of China $^{18}$ and the recommendations of the American Academy of Pediatrics. ${ }^{17}$ The present study did not recruit preterm infants weighing under $1000 \mathrm{~g}$ at birth or with gestational age of under 28 weeks. It is not known whether our schedule is also suitable for these extremely premature infants. It may be better to start hepatitis $\mathrm{B}$ vaccination when they weigh a minimum of $2000 \mathrm{~g}$ or are 2 months old, as suggested by the American Academy of Pediatrics.

This study was supported by Premature Baby Foundation of the Republic of China, grant No 8002.

1 Beasley RP, Hwang LY, Lin CC, Leu M, Stevens CE, Szmuness W, et al. Incidence of hepatitis B virus infections in preschool children in Taiwan. F Infect Dis 1982;146:198204 .

2 Tsen YJ, Chang MH, Hsu HY, Lee CY, Sung JL, Chen DS. Seroprevalence of hepatitis B virus infection in children in Taipei, 1989: five years after a mass hepatitis B vaccination program. F Med Virol 1991;34:96-9

3 Stevens CE, Beasley RP, Tsui JJ, Lee WC. Vertical transmission of hepatitis B antigen in Taiwan. $N$ Engl 7 Med 1975;292:771-4.

4 Lee PI, Chang MH, Lee CY, Hsu HY, Chen JS, Chen PJ, et al. Changes of serum hepatitis B virus DNA and aminotransferase levels during the course of chronic hepatitis B virus infection in children. Hepatology 1990;12:65760

5 Beasley RP, Huang LY, Lee CY, Lan CC, Roan CH, Huang FY, et al. Prevention of perinatally transmitted hepatitis B virus infections with hepatitis B immune globulin (HBIG) in combination with HB vaccine. Lancet 1983;ii:1099102 .

6 Lee CY, Huang LM, Chang MH, Hsu CY, Wu SJ, Sung JL, et al. The protective efficacy of recombinant hepatitis B vaccine in newborn infants of hepatitis $B$ e antigenpositive-hepatitis B surface antigen carrier mothers. Pediatr Infect Dis f 1991;10:299-303.

7 Stevens CE, Toy PT, Taylor PE, Lee T, Yip HY. Prospects for control of hepatitis $\mathrm{B}$ virus infection: implications of
childhood vaccination and long-term protection. Pediatrics 1992;90:170-3.

8 Lee PI, Lee CY, Huang LM, Chang MH. Long-term efficacy of recombinant hepatitis B vaccine and risk of 
natural infection in infants born to mothers with hepatitis B e antigen. F Pediatr 1995;126:716-21

9 Chen DS, Hsu NH, Sung JL, Hsu TC, Hsu ST, Kud al. A mass vaccination program in Taiwan against hepatitis $\mathrm{B}$ virus infection in infants of hepatitis $\mathrm{B}$ surface antigencarrier mothers. $\mathcal{F} A M A$ 1987;257:2597-603.

10 Chen HL, Chang MH, Ni YH, Hsu HY, Lee PI, Lee CY, al. Seroepidemiology of hepatitis B virus infection in children: ten years of mass vaccination in Taiwan. $\mathcal{F} A M A$ 1996;276:906-8

11 Lau YL, Tam AYC, Ng KW, Tsoi NS, Lam B, Lam P, et al. Response of preterm infants to hepatitis $\mathrm{B}$ vaccine. $\mathcal{F}$ Pediatr 1992;121:962-5.

12 Chirico G, Belloni C, Gasparoni A, Cerbo RM, Rondini G, Klersy $C$, et al. Hepatitis B immunization in infants of hepatitis B surface 1993;92:717-9.

13 Chawareewong S, Jirapongsa A, Lokaphadhana K. Immune response to hepatitis B vaccine in premature neonates. response to hepatitis B vacine in premature neonates.
Southeast Asian f Trop Med Public Health 1991;22:39-40.
14 Del Canho R, Grosheide PM, Gerards LJ, Heijtink RA, Schalm SW. Hepatitis B vaccination and preterm infants. Pediatr Infect Dis $\mathcal{F}$ 1993;12:407-8.

15 Lee CY, Lee PI, Huang LM, Chen JM, Chang MH. A simplified schedule to integrate the hepatitis $B$ vaccine into an expanded program of immunization in endemic countries. 7 Pediatr 1997;130:81-6.

16 Lee PI, Lee CY, Huang LM, Chen JM, Chang MH. A follow-up study of combined vaccination with plasmaderived and recombinant hepatitis $B$ vaccines in infants. Vaccine 1995;13:1685-9.

17 American Academy of Pediatrics, Committee on Infectious Diseases. Update on timing of hepatitis B vaccination for premature infants and for children with lapsed immunization. Pediatrics 1994;94:403-4.

18 Advisory Committee for Immunization Practice, Department of Health, Republic of China. Handbook for Immunization and Important Infectious Diseases. Taipei: zation and Important Infectious Diseases. Taipe:
Department of Health, Republic of China, 1995: 52-7. 